\title{
Estimation of uranium sources in environmental samples using the isotopic ratio determination
}

\author{
J.SHIKIMORI $^{1 *}$, T.OHNO $^{1}$, Y.FUKAMI ${ }^{1}$, Y.IGARASHI ${ }^{2}$
}

${ }^{1}$ Gakushuin University, Tokyo 171-8588, Japan

(*correspondence: 19142014@gakushuin.ac.jp)

${ }^{2}$ The University of Kyoto, Osaka 590-0494, Japan

Natural uranium contains ${ }^{234} \mathrm{U},{ }^{235} \mathrm{U}$ and ${ }^{238} \mathrm{U}$, especially the fissile isotope ${ }^{235} \mathrm{U}$ is used as nuclear fuel. Most of ${ }^{235} \mathrm{U}$ undergo fission by neutron capture, while some produce ${ }^{236} \mathrm{U}$ by ${ }^{235} \mathrm{U}(\mathrm{n}, \gamma){ }^{236} \mathrm{U}$ reaction. Thus, ${ }^{236} \mathrm{U}$ has been used as a tracer to investigate the distribution of anthropogenic uranium. The sources in the environment are nuclear weapons tests, nuclear power plant accidents, fuel reprocessing, and decommissioning of NPPs. Among them, in nuclear fuel reprocessing facilities, the by-product of uranium enrichment is depleted uranium (DU). DU contains ${ }^{236} \mathrm{U}$ and less ${ }^{235} \mathrm{U}$ than natural uranium, which had been used as an industrial catalyst. Thus, the release of the DU into the environment can be determined as increase of the ${ }^{236} \mathrm{U}^{238} \mathrm{U}$ ratio and decrease of the ${ }^{235} \mathrm{U} /{ }^{238} \mathrm{U}$ ratio, simultaneously. In this study, we examined the anthropogenic sources of uranium in the environment using interannual variations of the isotopic ratios.

Atmospheric depositions and marine sediments [1] were collected in Tokyo. The samples were digested with a mixture of nitric acid and hydrofluoric acid, then were leached with nitric acid. The matrix elements were removed using UTEVA resin, after that the uranium isotopes were analyzed by an ICP-MS/MS (Agilent 8800, Agilent Technologies). For the ${ }^{236} \mathrm{U} /{ }^{238} \mathrm{U}$ measurement, we employed a desolvating nebulizer (Aridus II , Cetac Technologies) to reduce the interferences by hydride ions [2].

In the atmospheric depositions, the principal features were as follows; the ${ }^{236} \mathrm{U} /{ }^{238} \mathrm{U}$ ratio peaked in 1963 and the 1970 s, while the ${ }^{235} U /{ }^{238} U$ ratio displayed less than the natural one in the $1970 \mathrm{~s}$. The peak of ${ }^{236} \mathrm{U} /{ }^{238} \mathrm{U}$ in 1963 corresponded to that recognized as representing global fallout. The increase of ${ }^{236} \mathrm{U} /{ }^{238} \mathrm{U}$ and the decrease of ${ }^{235} \mathrm{U} /{ }^{238} \mathrm{U}$ observed simultaneously in the 1970s suggests that DU had been released into the environment. The DU could originate from the industrial use. In the marine sediments, the ${ }^{236} \mathrm{U} /{ }^{238} \mathrm{U}$ exhibited peaks in the 1970s. It was suggested that the main anthropogenic source of uranium could not be the global fallout. In this presentation, we would like to discuss the possible anthropogenic sources of the uranium.

[1] Sakata et al. (2013) Atmos. Environ. 42, 5913-5922.

[2] Tanimizu et al. (2013) J Anal At Spectrom. 28, 1372-1376. 